\title{
Low serum testosterone is associated with tumor aggressiveness and poor prognosis in prostate cancer
}

\author{
HUAKANG TU ${ }^{1}$, JIAN GU ${ }^{1}$, QING H. MENG ${ }^{2}$, JERI KIM ${ }^{3}$, SARA STROM ${ }^{1}$, JOHN W. DAVIS ${ }^{4}$, YONGGANG HE ${ }^{5}$, \\ ELIZABETH A. WAGAR ${ }^{2}$, TIMOTHY C. THOMPSON ${ }^{3}$, CHRISTOPHER J. LOGOTHETIS $^{3}$ and XIFENG WU ${ }^{1}$ \\ Departments of ${ }^{1}$ Epidemiology, ${ }^{2}$ Laboratory Medicine, ${ }^{3}$ Genitourinary Medical Oncology and ${ }^{4}$ Urology, \\ The University of Texas MD Anderson Cancer Center, Houston, TX 77030, USA; ${ }^{5}$ Department of Surgery, \\ Ruijin Hospital, Shanghai Jiao Tong University School of Medicine, Shanghai 200025, P.R. China
}

Received April 14, 2016; Accepted November 1, 2016

DOI: $10.3892 / \mathrm{ol} .2017 .5616$

\begin{abstract}
Serum testosterone is a potential marker to distinguish between indolent and aggressive prostate cancer (PCa). The present study aimed to investigate whether low levels of total serum testosterone at diagnosis were associated with aggressive $\mathrm{PCa}$ and poor clinical outcomes. In total, 762 non-Hispanic Caucasian men with previously untreated PCa were recruited from The University of Texas MD Anderson Cancer Center (Houston, TX, USA). Patients were categorized into three groups based on their total serum testosterone levels according to clinical guidelines [low $(<230 \mathrm{ng} / \mathrm{dl})$, intermediate (230-350 ng/dl) and normal (>350 ng/dl)]. PCa aggressiveness (low-, intermediate- or high-risk, or metastatic) was compared using multinomial logistic regression. Rates of disease progression, mortality from any cause and PCa-specific mortality were compared using the multivariate Cox proportional hazards model. Testosterone levels significantly decreased as $\mathrm{PCa}$ aggressiveness increased $(\mathrm{P}<0.001)$. Compared with the normal testosterone group, the low testosterone group had 2.9-fold (OR, 2.92; 95\% CI, 1.74-4.90; P<0.001), 5.6-fold (OR, 5.63; 95\% CI, 3.14-10.12; $\mathrm{P}<0.001)$ and 72.4-fold (OR, 72.40; 95\% CI, 20.89-250.89; $\mathrm{P}<0.001)$ increased risks of having intermediate-risk, high-risk and metastatic $\mathrm{PCa}$, respectively. Furthermore, low levels of testosterone were significantly associated with a 10.7-fold (HR, 10.68; 95\% CI, 1.35-84.44; $\mathrm{P}=0.03$ ) increased risk of $\mathrm{PCa}$-specific mortality. The results of the present study indicate that low levels of total serum
\end{abstract}

Correspondence to: Dr Xifeng Wu, Department of Epidemiology, The University of Texas MD Anderson Cancer Center, Unit 1340, 1155 Pressler Street, Houston, TX 77030, USA

E-mail: xwu@mdanderson.org

Abbreviations: PCa, prostate cancer; PSA, prostate-specific antigen; BMI, body mass index; OR, odds ratio; CI, confidence interval; HR, hazard ratio; $\mathrm{BCR}$, biochemical recurrence

Key words: androgen, testosterone, prostate cancer, aggressiveness, progression, survival testosterone at diagnosis are associated with aggressive $\mathrm{PCa}$ and predict poor PCa-specific survival.

\section{Introduction}

Prostate cancer $(\mathrm{PCa})$ is the most common cancer among men in the US (1). Use of the prostate-specific antigen (PSA) test in PCa screening is controversial, due to uncertainty surrounding its benefits and risks (2); the PSA test can identify asymptomatic, indolent tumors, leading to unnecessary treatments and significant side effects associated with these treatments $(1,3)$. The prevalence of clinically indolent tumors has been estimated to range from 30 to $70 \%$ in men aged $>60$ years $(4,5)$. Therefore, a reliable method for distinguishing between indolent and aggressive $\mathrm{PCa}$ is urgently required.

Multiple pre-treatment risk stratification systems have been developed for patients with PCa (6). Among them, the D'Amico risk stratification is the most widely used; it groups patients with localized PCa into three strata (low-, intermediate- and high-risk), based on total Gleason score, clinical stage and PSA levels at diagnosis (7). However, this existing three-group risk stratification system is insufficient to predict tumor aggressiveness as each risk group, particularly the intermediate-risk group, remains heterogeneous with regard to prognosis and treatment management (6). Current research is actively exploring new markers to enable better distinction between indolent and aggressive disease and to minimize unnecessary treatment (1).

Testosterone is essential for the normal growth, cytodifferentiation and maintenance of prostate tissue (8). High testosterone levels were previously considered to lead to the potential development of $\mathrm{PCa}$ and more rapid growth of the tumor $(9,10)$. However, studies on the association between testosterone and PCa risk have produced conflicting results $(8,9)$. Numerous studies have demonstrated that low, rather than high, testosterone levels at diagnosis were associated with various markers of poor prognosis, including an advanced pathological stage, higher Gleason scores, higher PSA levels, seminal vesicle invasion and positive surgical margins (11-25). Few studies have further investigated whether low levels of testosterone predict poor prognosis. 
The present study investigated whether low levels of total serum testosterone at diagnosis were associated with aggressive features of PCa. In addition, the study further investigated whether low levels of testosterone could predict poor clinical outcomes, including disease progression, mortality from any cause and $\mathrm{PCa}$-specific mortality, independently of the commonly used clinical parameters.

\section{Materials and methods}

Study population and data collection. The present study was approved by Institutional Review Board of the University of Texas MD Anderson Cancer Center (Houston, TX, USA) and informed consent was obtained from all individual participants included in the study. Recruitment and data collection for the present study was conducted as previously described (26,27). Briefly, a total of 762 non-Hispanic Caucasian men with previously untreated, newly diagnosed $\mathrm{PCa}$, who were treated at The University of Texas MD Anderson Cancer Center between September 2000 and February 2012 and who had total serum testosterone measured were included in the current study. The morning total serum testosterone levels were measured as part of a standard panel of tests evaluating patients' overall baseline condition prior to treatment. Information on demographics, body mass index (BMI) and smoking history was collected at patient registration using self-administered questionnaires. Clinical data, including diagnosis date, PSA level at diagnosis, biopsy-proven Gleason score, tumor-node-metastasis classification and treatments, was abstracted by a chart review of the patients' medical records. Data regarding disease progression was abstracted for 453 patients who had a localized tumor and received active treatments. For patients with locally advanced (T3a, T3b or T4) or metastatic tumors, follow-up PSA tests were performed every 3-6 months for 5 years. Following definitive therapy, PSA tests were performed every 3-6 months for the first 5 years, every 6-12 months for the subsequent 5 years, and annually thereafter.

Definition of tumor aggressiveness and clinical outcomes. Aggressiveness of localized tumors was defined as follows based on the D'Amico risk criteria (7): Low-risk (total Gleason score $\leq 6$; clinical tumor classification of T1-T2a; PSA $\leq 10 \mathrm{ng} / \mathrm{ml}$ ); intermediate-risk (Gleason score equal to 7; and/or clinical tumor classification of T2b; and/or PSA level $>10$ and $\leq 20 \mathrm{ng} / \mathrm{ml}$ ); and high-risk (Gleason score $\geq 8$; or clinical tumor classification of T2c-T4; or PSA $>20 \mathrm{ng} / \mathrm{ml}$ ). In addition, metastatic tumors were defined as the most aggressive form of PCa, as they confer a poor prognosis (28). Disease progression in patients with localized tumors was defined as the presence of biochemical recurrence (BCR), local recurrence or distant metastasis (whichever was recorded first), as local recurrence or distant metastasis may occur with no record of an increase in PSA in certain cases. According to the American Urological Association Prostate Cancer Guidelines Panel (29), BCR in patients treated with radical prostatectomy is defined as a PSA $\geq 0.2 \mathrm{ng} / \mathrm{ml}$ with a second confirmatory level of PSA $>0.2 \mathrm{ng} / \mathrm{ml}$. The Radiation Therapy Oncology Group-American Society for Therapeutic Radiology and Oncology (30) defines BCR in patients with PCa who received radiotherapy as a rise in PSA of $\geq 2 \mathrm{ng} / \mathrm{ml}$ above the lowest level following treatment (the nadir).

Statistical analysis. According to an international consensus statement (31), patients were categorized into the following three groups based on total serum testosterone levels: Low $(<230 \mathrm{ng} / \mathrm{dl})$, intermediate (230-350 $\mathrm{ng} / \mathrm{dl})$ and normal ( $>350 \mathrm{ng} / \mathrm{dl}$ ). The distribution of selected characteristics of the three testosterone groups were compared using the nonparametric K-sample test on the equality of medians for continuous variables and the Chi-squared test for categorical variables. Odds ratios (ORs) with 95\% confidence intervals (CIs) were calculated to measure the association between serum testosterone levels and $\mathrm{PCa}$ aggressiveness, using multinomial logistic regression with the low-risk form of $\mathrm{PCa}$ as the reference outcome, following adjustment for potential confounding variables, including age, BMI and smoking status. In addition, a restricted cubic spline was used to model the non-linear association between serum testosterone levels and PCa aggressiveness. Four knots were used for this model and the 95th percentile $(675 \mathrm{ng} / \mathrm{dl})$ was chosen as the reference level.

The 'time to event' of the clinical outcomes was defined as the length of time between diagnosis and the clinical outcome of interest (mortality) or the last follow-up. Kaplan-Meier estimator survival curves and log-rank tests were used to assess the association between serum testosterone levels and clinical outcomes across the three testosterone groups. A multivariate Cox proportional hazards model was used to estimate hazard ratios (HRs) and 95\% CIs, following adjustment for age, tumor aggressiveness (low-, intermediate- or high-risk, or metastatic) and treatment.

All statistical analyses were performed using Stata software (version 13; StataCorp, College Station, TX, USA) and all tests were two-tailed. $\mathrm{P}<0.05$ was considered to indicate a statistically significant difference.

\section{Results}

Patient characteristics. Specific characteristics of the patients, overall and by total serum testosterone levels, are summarized in Table I. The majority of the participants had a total Gleason score of 7, T1 tumor stage, and PSA $<10 \mathrm{ng} / \mathrm{ml}$ at diagnosis, and were treated with radiotherapy. Between the three testosterone groups, patients differed significantly in terms of BMI at diagnosis, total Gleason score, clinical tumor classification, lymphatic metastasis at diagnosis, distant metastasis at diagnosis, clinicopathological characteristics, PSA levels at diagnosis and initial primary treatment $(\mathrm{P}<0.001)$. In particular, nearly half $(47.9 \%)$ of the patients with low serum testosterone had tumors with a total Gleason score of $\geq 8$ compared with only $11.7 \%$ of patients with normal serum testosterone levels. Distant metastases at diagnosis were present in $19.5 \%$ of patients in the low serum testosterone group compared with $1.8 \%$ in the normal serum testosterone group.

Association between total serum testosterone levels and PCa aggressiveness. As shown in Fig. 1A, total serum testosterone levels decreased as aggressiveness increased $(\mathrm{P}<0.001)$. In addition, total serum testosterone levels decreased with increases in the total Gleason score of the tumor $(\mathrm{P}<0.001$; 
Table I. Characteristics of the patients with prostate cancer in the present study.

\begin{tabular}{|c|c|c|c|c|c|}
\hline \multirow[b]{2}{*}{ Characteristic } & \multirow[b]{2}{*}{ All groups } & \multicolumn{3}{|c|}{ Total serum testosterone levels } & \multirow[b]{2}{*}{ P-value } \\
\hline & & Low & Intermediate & Normal & \\
\hline Total number of patients & 762 & 316 & 162 & 284 & - \\
\hline Age at diagnosis, years & $65.0(31.0-90.0)$ & $65.0(43.0-82.0)$ & $64.0(43.0-84.0)$ & $65.0(31.0-90.0)$ & 0.32 \\
\hline $\mathrm{BMI}$ at diagnosis ${ }^{\mathrm{a}}, \mathrm{kg} / \mathrm{m}^{2}$ & $28.7(19.8-54.4)$ & $29.2(20.9-54.4)$ & $29.3(20.9-47.0)$ & $27.3(19.8-42.8)$ & $<0.001$ \\
\hline Follow-up time ${ }^{\mathrm{b}}$, months & $44.4(0.7-156.8)$ & $45.3(0.9-118.9)$ & $41.5(0.8-137.3)$ & $44.2(0.7-156.8)$ & 0.53 \\
\hline Smoking status at diagnosis & & & & & 0.44 \\
\hline Non-smoker & $332(44.0)$ & $133(42.1)$ & $71(44.7)$ & $128(45.7)$ & \\
\hline Former smoker & $364(48.2)$ & $158(50.0)$ & $80(50.3)$ & $126(45.0)$ & \\
\hline Current smoker & $59(7.8)$ & $25(7.9)$ & $8(5.0)$ & $26(9.3)$ & \\
\hline Total Gleason score & & & & & $<0.001$ \\
\hline$\leq 6$ & $255(34.0)$ & $42(13.7)$ & $72(44.4)$ & $141(50.0)$ & \\
\hline 7 & $295(39.3)$ & $118(38.4)$ & $69(42.6)$ & $108(38.3)$ & \\
\hline$\geq 8$ & $201(26.8)$ & $147(47.9)$ & $21(13.0)$ & $33(11.7)$ & \\
\hline Clinical tumor classification & & & & & $<0.001$ \\
\hline $\mathrm{T} 1$ & $415(54.5)$ & $109(34.5)$ & $107(66.0)$ & $199(70.1)$ & \\
\hline $\mathrm{T} 2$ & $216(28.3)$ & $115(36.4)$ & $39(24.1)$ & $62(21.8)$ & \\
\hline $\mathrm{T} 3-\mathrm{T} 4$ & $102(13.4)$ & $69(21.8)$ & $14(8.6)$ & $19(6.7)$ & \\
\hline $\mathrm{Tx}$ & $29(3.8)$ & $23(7.3)$ & $2(1.2)$ & $4(1.4)$ & \\
\hline Presence of lymphatic metastasis at diagnosis & & & & & $<0.001$ \\
\hline Yes & $55(7.5)$ & $52(17.3)$ & $2(1.3)$ & $1(0.4)$ & \\
\hline No & $680(92.5)$ & $248(82.7)$ & $154(98.7)$ & $278(99.6)$ & \\
\hline Presence of distant metastasis at diagnosis & & & & & $<0.001$ \\
\hline Yes & $70(9.3)$ & $61(19.5)$ & $4(2.5)$ & $5(1.8)$ & \\
\hline No & $683(90.7)$ & $252(80.5)$ & $155(97.5)$ & $276(98.2)$ & \\
\hline PSA at diagnosis, $\mathrm{ng} / \mathrm{ml}$ & & & & & $<0.001$ \\
\hline$<10$ & $585(77.1)$ & $207(65.7)$ & $139(85.8)$ & $239(84.8)$ & \\
\hline $10-20$ & $73(9.6)$ & $39(12.4)$ & $13(8.0)$ & $21(7.4)$ & \\
\hline$>20$ & $101(13.3)$ & $69(21.9)$ & $10(6.2)$ & $22(7.8)$ & \\
\hline Initial primary treatment & & & & & $<0.001$ \\
\hline Radical prostatectomy & $152(20.0)$ & $57(18.0)$ & $43(26.5)$ & $52(18.3)$ & \\
\hline Radiotherapy & $293(38.5)$ & $154(48.7)$ & $54(33.3)$ & $85(29.9)$ & \\
\hline Hormone therapy & $78(10.2)$ & $69(21.8)$ & $1(0.6)$ & $8(2.8)$ & \\
\hline Surveillance or unknown ${ }^{\mathrm{c}}$ & $230(30.2)$ & $30(9.5)$ & $61(37.7)$ & $139(48.9)$ & \\
\hline Other treatment ${ }^{\mathrm{d}}$ & $9(1.2)$ & $6(1.9)$ & $3(1.9)$ & $0(0)$ & \\
\hline
\end{tabular}

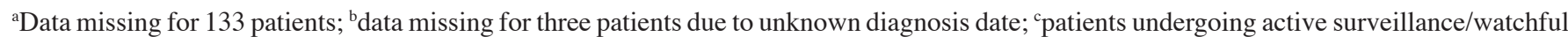
waiting or whose initial treatment information was unavailable; ${ }^{\mathrm{d}}$ chemotherapy, cryoablation, high-intensity focused ultrasound or transurethral resection of prostate. Data are presented as median (range) for continuous variables, and number of patients (\%) for categorical variables. Total serum testosterone levels were classified as normal ( $>350 \mathrm{ng} / \mathrm{dl})$, intermediate (230-350 ng/dl) or low ( $<230 \mathrm{ng} / \mathrm{dl})$. BMI, body mass index; PSA, prostate-specific antigen. P-values were from the comparison of the three testosterone groups using the nonparametric K-sample test on the equality of medians for continuous variables and the Chi-squared test for categorical variables.

Fig. 1B), clinical tumor stage ( $\mathrm{P}<0.001$; Fig. 1C) and PSA level at diagnosis $(\mathrm{P}<0.001$; Fig. 1D). Furthermore, among patients with $\mathrm{PCa}$ who underwent radical prostatectomy (Fig. 2), there were significantly lower total serum testosterone levels in patients with advanced pathological stage tumors (T3-T4 or metastatic) ( $\mathrm{P}=0.001$ vs. T1-T2; Fig. 2B) and in patients with positive seminal vesicle invasion $(\mathrm{P}=0.002$ vs. negative; Fig. 2C).
Table II shows the adjusted associations between total serum testosterone levels and tumor aggressiveness. Patients with low total serum testosterone levels had statistically significant 2.9-fold (OR, 2.92; 95\% CI, 1.74-4.90; $\mathrm{P}<0.001$ ), 5.6-fold (OR, 5.63; 95\% CI, 3.14-10.12; $\mathrm{P}<0.001)$ and 72.4-fold (OR, 72.40; 95\% CI, 20.89-250.89; $\mathrm{P}<0.001)$ increased risks of having intermediate-risk, high-risk and metastatic form of $\mathrm{PCa}$, respectively, compared with patients with normal 

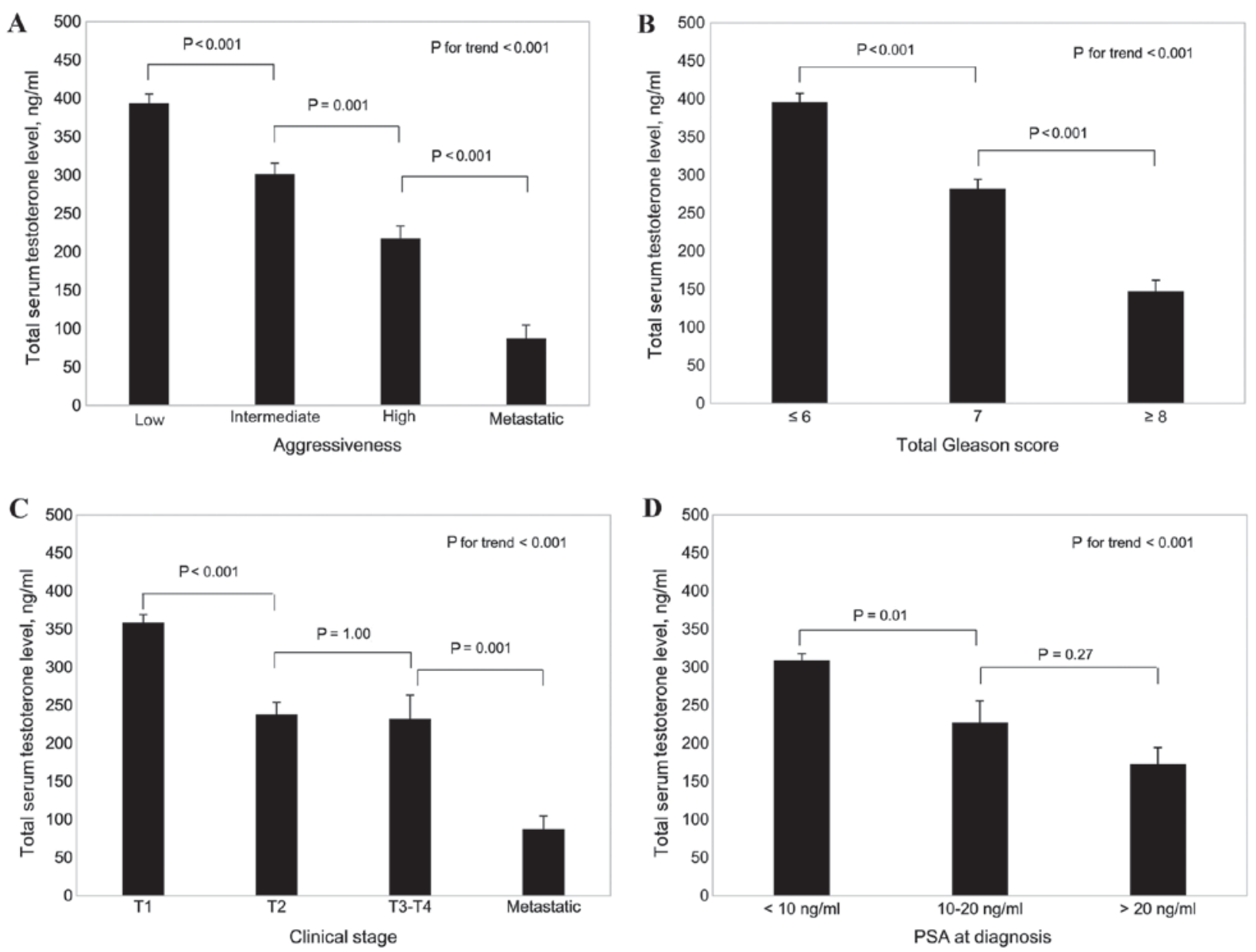

Figure 1. Association between total serum testosterone levels in patients with prostate cancer and (A) tumor aggressiveness, (B) total Gleason score, (C) clinical stage of tumor and (D) PSA levels at diagnosis. Results are presented as the mean \pm standard error. PSA, prostate-specific antigen.

total serum testosterone levels. Intermediate levels of total serum testosterone were not significantly associated with PCa aggressiveness.

A restricted cubic spline was used to model the association between total serum testosterone levels and the intermediateor high-risk/metastatic forms of PCa (Fig. 3). As shown in Fig. 3A, total serum testosterone levels $>200 \mathrm{ng} / \mathrm{dl}$ were not significantly associated with the intermediate-risk form of PCa; however, total serum testosterone levels $<200 \mathrm{ng} / \mathrm{dl}$ were significantly associated with intermediate-risk form of $\mathrm{PCa}$. A similar association was found between total serum testosterone levels and high-risk/metastatic PCa (Fig. 3B); however, when total serum testosterone levels reached $>150 \mathrm{ng} / \mathrm{dl}$ an association was notable.

Association between total serum testosterone levels and clinical outcomes. As shown in Fig. 4, compared with the group with normal levels of total serum testosterone, the group with low levels had a significantly increased risk of disease progression (HR, 2.10; 95\% CI, 1.09-4.07; P=0.03; Fig. 4A), mortality from all causes (HR, 3.80; 95\% CI, 1.99-7.28; $\mathrm{P}<0.001$; Fig. 4B) and mortality due to $\mathrm{PCa}$ (HR, 28.14; 95\% CI, 3.83-206.97; P<0.001; Fig. 4C). Table III shows the multivariate adjusted results. Compared with normal testosterone levels, low levels of testosterone were associated with a non-significant 1.9-fold (HR, 1.90; 95\% CI, 0.89-4.03; P=0.10) increased risk of mortality from all causes and a significant 10.7-fold (HR, 10.68; 95\% CI, 1.35-84.44; $\mathrm{P}=0.03$ ) increased risk of death due to $\mathrm{PCa}$.

\section{Discussion}

In a cohort of 762 patients with PCa, the present study observed that low levels of total serum testosterone at diagnosis were associated with aggressive features of PCa. Furthermore, the results of the current study indicate that low total serum testosterone levels predict poor PCa-specific survival (i.e., mortality due to PCa). To the best of our knowledge, this is the first study to show an association between total serum testosterone levels and PCa-specific mortality.

The present study demonstrated that, compared with high levels of total serum testosterone at the time of diagnosis, low total serum testosterone levels at the time of diagnosis were associated with aggressive features of $\mathrm{PCa}$, which is consistent with the results of previous studies (11-25). A previous pooled analysis of 18 prospective studies identified that pre-diagnosis serum testosterone levels were not associated with the high-risk form of $\mathrm{PCa}$ (32); however, the testosterone levels in this analysis were measured years prior to PCa diagnosis and a different definition of high-risk form of PCa was used.

The results of the current study suggest that low total serum testosterone levels predict poor prognosis in patients with $\mathrm{PCa}$. 
Table II. Association between total serum testosterone levels at diagnosis and PCa aggressiveness.

Testosterone levels

PCa aggressiveness

Normal

Intermediate

Low

P-value for trend

Low-risk localized PCa, number of patients (\%) 128 (54.7)

Intermediate-risk localized $\mathrm{PCa}$

Number of patients (\%)

Adjusted $^{a}$ OR (95\% CI)

$\begin{array}{lc}101(40.1) & 58(23.0) \\ \text { Reference } & 1.03(0.63-1.71)\end{array}$

$67(28.6)$

$39(16.7)$

$93(36.9)$

$2.92(1.74-4.90)^{\mathrm{b}}$

$<0.001$

High-risk localized PCa

Number of patients (\%)

Adjusted $^{\text {a }}$ OR (95\% CI)

49 (27.2)

$32(17.8)$

$99(55.0)$

Reference

$1.23(0.67-2.28)$

$5.63(3.14-10.12)^{b}$

$<0.001$

Metastatic PCa

Number of patients (\%)

Adjusted $^{\mathrm{a}}$ OR (95\% CI)
$6(6.3)$

$5(5.2)$
Reference $\quad 2.27(0.48-10.69) \quad 72.40(20.89-250.89)^{\mathrm{b}} \quad<0.001$
$85(88.5)$

Total serum testosterone levels were classified as normal (>350 ng/dl), intermediate (230-350 ng/dl) or low (<230 ng/dl). ${ }^{\mathrm{a} A d j u s t e d ~ f o r ~ a g e, ~ b o d y ~}$ mass index and smoking status; ${ }^{b} \mathrm{P}<0.05$ vs. normal testosterone level group via a multinomial logistic regression model. Multinomial logistic regression with the low-risk form of PCa was used as the reference outcome. PCa, prostate cancer; OR, odds ratio; CI, confidence interval. $\mathrm{P}$-values for each trend were obtained by including the three levels of testosterone as ordinal variables in a multinomial logistic regression model.
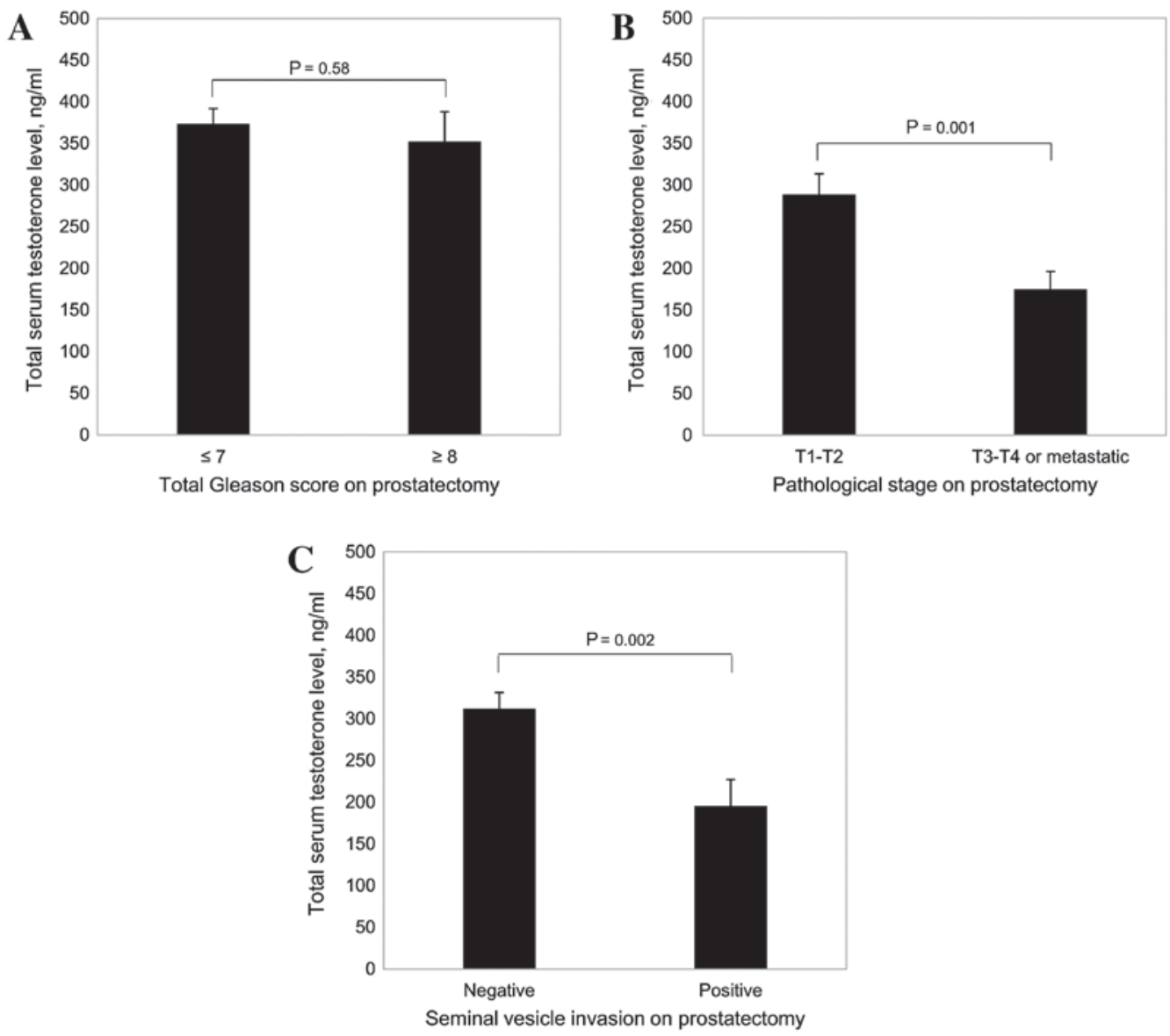

Figure 2. Association between total serum testosterone levels in patients with PCa who underwent radical prostatectomy and (A) total Gleason score, (B) pathological stage of the tumor and $(C)$ seminal vesicle invasion. Results are presented as the mean \pm standard error.

Three previous studies (33-35), of which two had small sample sizes $(34,35)$, have investigated this association in patients with metastatic PCa patients. Consistent with the present study, the results of these studies indicated that lower testosterone levels predicted poor overall $(33,34)$ and progression-free $(35)$ survival times in patients with metastatic PCa. Two previous studies 

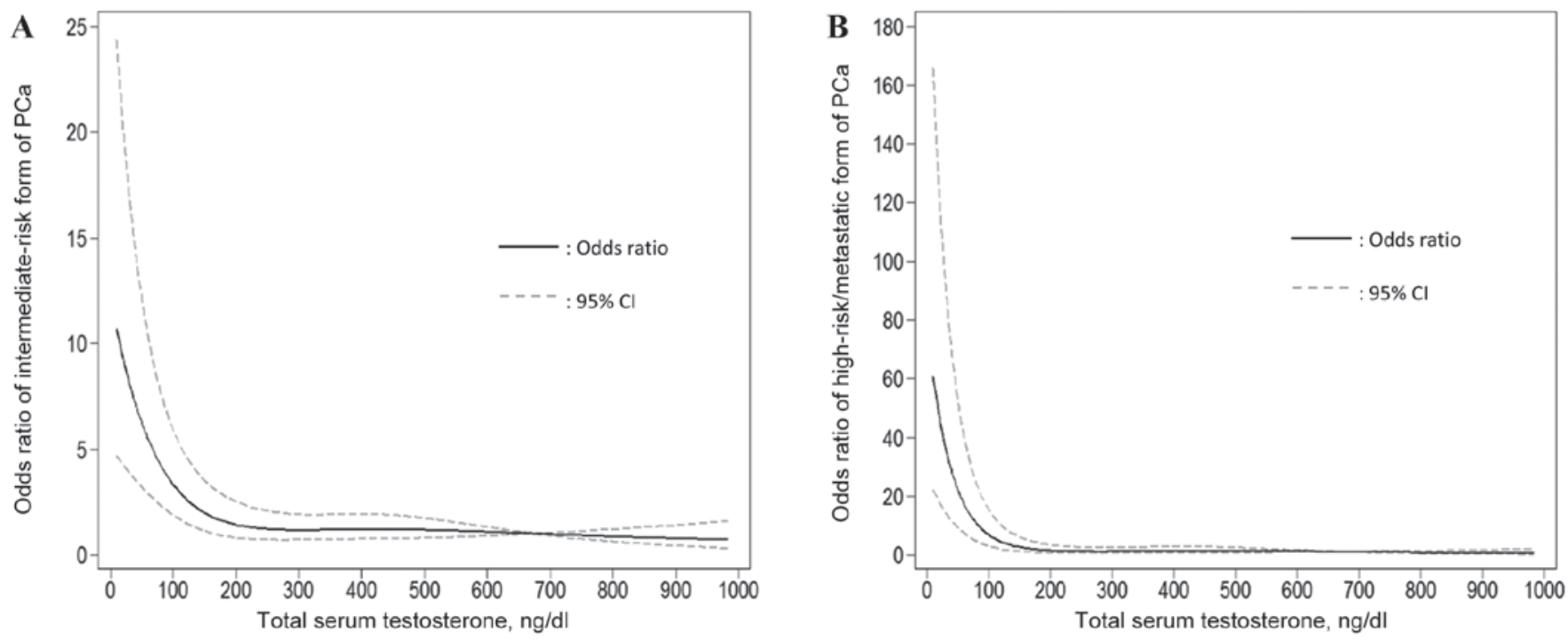

Figure 3. Restricted cubic spline modeling for the association between total serum testosterone levels and (A) intermediate-risk or (B) high-risk/metastatic forms of PCa compared with the low-risk form of PCa. Four knots were used in the modeling and the 95th percentile (675 ng/dl) was chosen as the reference level. PCa, prostate cancer; CI, confidence interval.
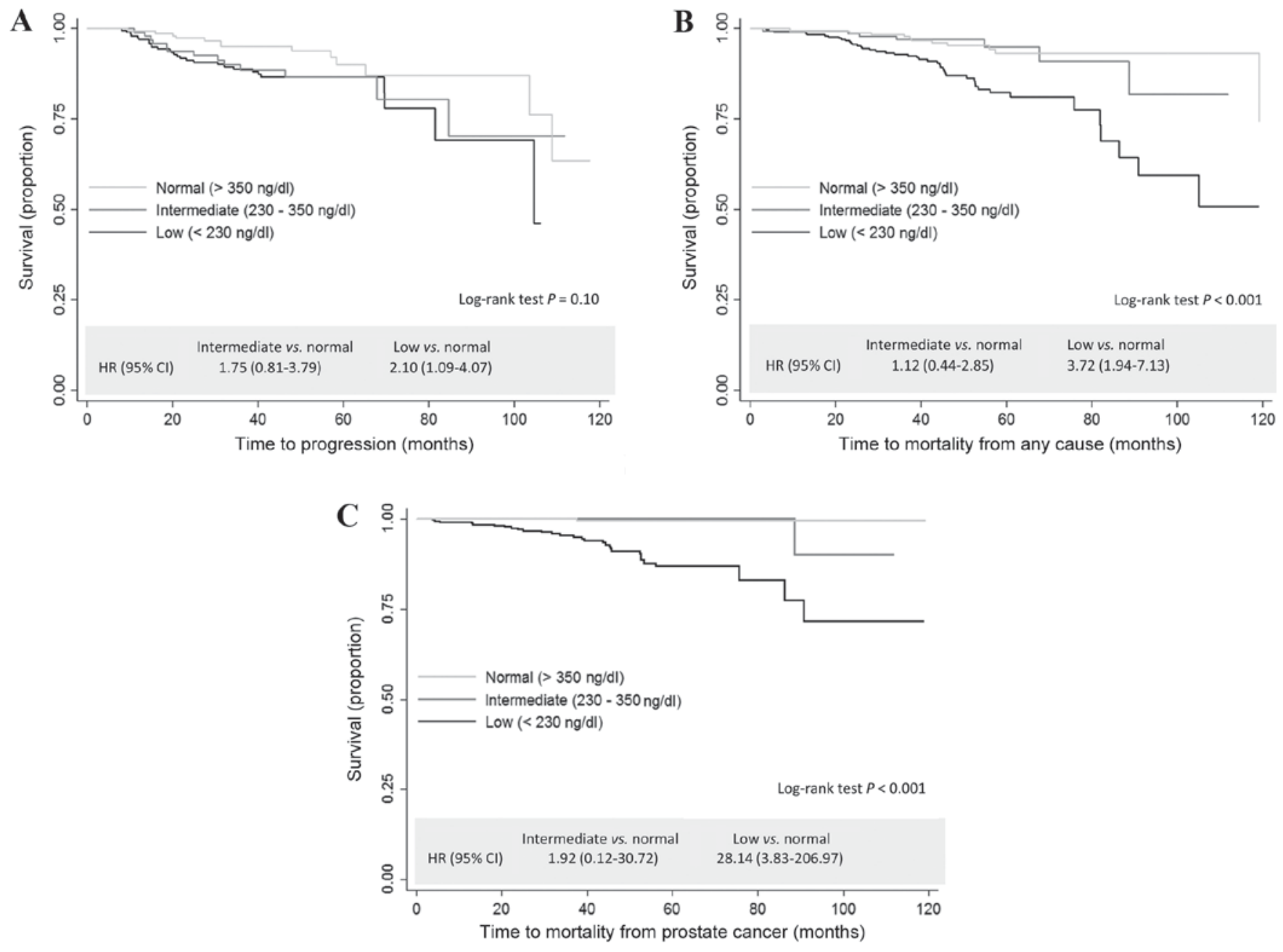

Figure 4. Unadjusted Kaplan-Meier estimator survival curves and HRs for the association between total serum testosterone levels and (A) disease progression, (B) mortality from all causes and (C) mortality due to prostate cancer. HR, hazard ratio; CI, confidence interval.

investigated the association between testosterone levels and BCR in patients with PCa who received radical prostatectomy, with inconsistent results; one study (36) indicated that lower testosterone levels predicted BCR, while the other study (24) 
Table III. Total serum testosterone levels at diagnosis and clinical outcomes of PCa patients.

Testosterone levels

\begin{tabular}{|c|c|c|c|c|}
\hline \multirow[b]{2}{*}{ Event occurrence } & & \multirow[b]{2}{*}{ P-value for trend } \\
\hline & Normal & Intermediate & Low & \\
\hline \multicolumn{5}{|c|}{ Disease progression $^{\mathrm{a}}$} \\
\hline Yes, n $(\%)$ & $13(8.4)$ & $13(13.1)$ & $29(14.6)$ & - \\
\hline No, n $(\%)$ & $142(91.6)$ & $86(86.9)$ & $170(85.4)$ & - \\
\hline $\operatorname{HR}(95 \% \mathrm{CI})$ & Reference & $1.74(0.79-3.89)$ & $1.14(0.51-2.52)$ & 0.69 \\
\hline P-value & N/A & 0.17 & 0.75 & - \\
\hline \multicolumn{5}{|c|}{ Mortality from any cause } \\
\hline Yes, n (\%) & $13(4.6)$ & $7(4.3)$ & $47(14.9)$ & - \\
\hline No, n $(\%)$ & $271(95.4)$ & $155(95.7)$ & $269(85.1)$ & - \\
\hline $\operatorname{HR}(95 \% \mathrm{CI})$ & Reference & $1.17(0.45-3.03)$ & $1.90(0.89-4.03)$ & 0.09 \\
\hline P-value & N/A & 0.75 & 0.1 & - \\
\hline \multicolumn{5}{|l|}{ Mortality from PCa } \\
\hline Yes, n (\%) & $1(0.4)$ & $1(0.6)$ & $30(9.5)$ & - \\
\hline No, n $(\%)$ & $283(99.6)$ & $161(99.4)$ & $286(90.5)$ & - \\
\hline $\operatorname{HR}(95 \% \mathrm{CI})$ & Reference & $1.84(0.11-31.92)$ & $10.68(1.35-84.44)$ & 0.02 \\
\hline $\mathrm{P}$-value & N/A & 0.81 & 0.03 & - \\
\hline
\end{tabular}

showed no association between these factors (24). In addition, low testosterone has been demonstrated to be an independent risk factor for disease progression/reclassification in patients with PCa on active surveillance (37).

The molecular mechanisms underlying the association demonstrated in the present study between low total serum testosterone levels at diagnosis and PCa aggressiveness or poor prognosis is unclear. One possibility is that low total serum testosterone levels may induce or select for molecular features that are indicative of more aggressive PCa or drug resistance (38). A previous study using NKX3-1/PTEN mutant mice suggested that prolonged exposure to low testosterone levels led to accelerated PCa progression and elevated expression of well-characterized markers of cancer progression, such as extracellular signal-regulated kinase/mitogen-activated protein kinase (39). Further gene expression profiling suggested that NKX3-1/PTEN mutant PCa mice with low testosterone levels and NKX3-1/PTEN mutant mice with androgen-independent $\mathrm{PCa}$ shared markedly similar gene expression profiles (39). The overlapping cluster included genes such as androgen receptor $(A R)$, matrix metalloproteinase 9, ETS1, runt-related transcription factor 1 and Vav guanine nucleotide exchange factor 3, which are associated with human $\mathrm{PCa}$ progression and hormone-refractory $\mathrm{PCa}$ (39). Previous human studies identified that patients with metastatic PCa with low serum testosterone levels had a worse response to endocrine therapy compared with patients with high serum testosterone levels $(33,38)$. Notably, data from the present study is consistent with the general model of oncogene derepression as a mechanism of PCa progression (40). In this model, inhibition of AR function can lead to derepression of oncogenes that are normally repressed by the fully functional AR, leading to $\mathrm{PCa}$ progression. It is conceivable that low serum testosterone may lead to activation of oncogenic pathways through this general mechanism.

The results of the present study have important clinical implications for the management and treatment of patients with $\mathrm{PCa}$. The results indicate that pre-treatment total serum testosterone levels could serve as a marker to distinguish between indolent and aggressive PCa. Notably, total serum testosterone levels could predict prognosis beyond the existing D'Amico three-group risk stratification (7) based on total Gleason score, clinical stage and PSA. If the findings of the current study are replicated and validated, clinicians may consider testing total serum testosterone routinely at diagnosis, in order to minimize over-treatment of indolent PCa and under-treatment of aggressive PCa.

The present study had several limitations. Firstly, despite the relatively large sample size, there was little data for clinical outcome due to the fact that the majority of the patients had localized disease. The association between total serum testosterone levels and $\mathrm{PCa}$-specific survival was statistically significant despite the small number of events; however, there was insufficient statistical power for the other two clinical outcomes (disease progression and mortality from all causes). Secondly, the study group consisted of a heterogeneous population, including patients with localized and metastatic tumors. The strengths of the current study were the systematic assessment of a large group of patients with PCa for a series of clinical outcomes, including disease 
progression, mortality from all causes and PCa-specific mortality, which provided a comprehensive assessment of the association between total serum testosterone levels and $\mathrm{PCa}$ prognosis. In addition, all serum testosterone assays, histopathological diagnoses, treatment procedures and collection of covariates were performed in a standard and consistent way across all patients. In future, studies with a larger sample size and measurements of bioavailable/free serum testosterone and other androgens, such dihydrotestosterone and androstenedione, are warranted.

In conclusion, the results of the present study using a large cohort support the mounting evidence of an association between low total serum testosterone levels at diagnosis and $\mathrm{PCa}$ aggressiveness. In addition, the results indicate that low total serum testosterone levels predict poor prognosis. Further observational studies are warranted to validate these results in a larger and more diverse population.

\section{Acknowledgements}

The present study was supported by the National Cancer Institute (National Institutes of Health, Bethesda, MA, USA; grant no. CA140388), the Cancer Prevention and Research Institute of Texas (Austin, TX, USA; grant no. RP140556) and the Center for Translational and Public Health Genomics (University of Texas MD Anderson Cancer Center, Houston, TX, USA).

\section{References}

1. American Cancer Society: Cancer Facts \& Figures 2015. American Cancer Society, Atlanta, GA, 2015.

2. Barry MJ: Screening for prostate cancer-the controversy that refuses to die. N Engl J Med 360: 1351-1354, 2009.

3. Welch HG and Albertsen PC: Prostate cancer diagnosis and treatment after the introduction of prostate-specific antigen screening: 1986-2005. J Natl Cancer Inst 101: 1325-1329, 2009.

4. Zlotta AR, Egawa S, Pushkar D, Govorov A, Kimura T, Kido M, Takahashi H, Kuk C, Kovylina M, Aldaoud N, et al: Prevalence of prostate cancer on autopsy: Cross-sectional study on unscreened Caucasian and Asian men. J Natl Cancer Inst 105: 1050-1058, 2013.

5. Welch HG and Black WC: Overdiagnosis in cancer. J Natl Cancer Inst 102: 605-613, 2010

6. Rodrigues G, Warde P, Pickles T, Crook J, Brundage M, Souhami L and Lukka H; Genitourinary Radiation Oncologists of Canada: Pre-treatment risk stratification of prostate cancer patients: A critical review. Can Urol Assoc J 6: 121-127, 2012.

7. D'Amico AV, Whittington R, Malkowicz SB, Schultz D, Blank K, Broderick GA, Tomaszewski JE, Renshaw AA, Kaplan I, Beard CJ and Wein A: Biochemical outcome after radical prostatectomy, external beam radiation therapy, or interstitial radiation therapy for clinically localized prostate cancer. JAMA 280 969-974, 1998

8. Isbarn H, Pinthus JH, Marks LS, Montorsi F, Morales A, Morgentaler A and Schulman C: Testosterone and prostate cancer: Revisiting old paradigms. Eur Urol 56: 48-56, 2009.

9. Klap J, Schmid M and Loughlin KR: The relationship between total testosterone levels and prostate cancer: A review of the continuing controversy. J Urol 193: 403-413, 2015.

10. Morgentaler A: Testosterone and prostate cancer: An historical perspective on a modern myth. Eur Urol 50: 935-939, 2006.

11. García-Cruz E, Piqueras M, Huguet J, Peri L, Izquierdo L, Musquera M, Franco A, Alvarez-Vijande R, Ribal MJ and Alcaraz A: Low testosterone levels are related to poor prognosis factors in men with prostate cancer prior to treatment. BJU Int 110: E541-E546, 2012.

12. Morgentaler A: Turning conventional wisdom upside-down: Low serum testosterone and high-risk prostate cancer. Cancer 117: $3885-3888,2011$
13. Imamoto T, Suzuki H, Fukasawa S, Shimbo M, Inahara M, Komiya A, Ueda T, Shiraishi T and Ichikawa T: Pretreatment serum testosterone level as a predictive factor of pathological stage in localized prostate cancer patients treated with radical prostatectomy. Eur Urol 47: 308-312, 2005.

14. Schatzl G, Madersbacher S, Thurridl T, Waldmüller J, Kramer G, Haitel A and Marberger M: High-grade prostate cancer is associated with low serum testosterone levels. Prostate 47: 52-58, 2001.

15. Yano M, Imamoto T, Suzuki H, Fukasawa S, Kojima S, Komiya A, Naya Y and Ichikawa T: The clinical potential of pretreatment serum testosterone level to improve the efficiency of prostate cancer screening. Eur Urol 51: 375-380, 2007.

16. Massengill JC, Sun L, Moul JW, Wu H, McLeod DG, Amling C, Lance R, Foley J, Sexton W, Kusuda L, et al: Pretreatment total testosterone level predicts pathological stage in patients with localized prostate cancer treated with radical prostatectomy. J Urol 169: 1670-1675, 2003.

17. Isom-Batz G, Bianco FJ Jr, Kattan MW, Mulhall JP, Lilja H and Eastham JA: Testosterone as a predictor of pathological stage in clinically localized prostate cancer. J Urol 173: 1935-1937, 2005.

18. Teloken C, Da Ros CT, Caraver F, Weber FA, Cavalheiro AP and Graziottin TM: Low serum testosterone levels are associated with positive surgical margins in radical retropubic prostatectomy: Hypogonadism represents bad prognosis in prostate cancer. J Urol 174: 2178-2180, 2005.

19. San Francisco IF, Regan MM, Dewolf WC and Olumi AF: Low age adjusted free testosterone levels correlate with poorly differentiated prostate cancer. J Urol 175: 1341-1346, 2006.

20. Leon P, Seisen T, Cussenot O, Drouin SJ, Cattarino S, Compérat E, Renard-Penna R, Mozer P, Bitker MO and Rouprêt M: Low circulating free and bioavailable testosterone levels as predictors of high-grade tumors in patients undergoing radical prostatectomy for localized prostate cancer. Urol Oncol 33: 384.r21-e27, 2015.

21. Salonia A, Gallina A, Briganti A, Abdollah F, Suardi N, Capitanio U, Colombo R, Freschi M, Rigatti P and Montorsi F: Preoperative hypogonadism is not an independent predictor of high-risk disease in patients undergoing radical prostatectomy. Cancer 117: 3953-3962, 2011.

22. Ide H, Yasuda M, Nishio K, Saito K, Isotani S, Kamiyama Y, Muto $S$ and Horie $S$ : Development of a nomogram for predicting high-grade prostate cancer on biopsy: The significance of serum testosterone levels. Anticancer Res 28: 2487-2492, 2008.

23. Dai B, Qu Y, Kong Y, Ye D, Yao X, Zhang S, Wang C, Zhang H and Yang W: Low pretreatment serum total testosterone is associated with a high incidence of Gleason score 8-10 disease in prostatectomy specimens: Data from ethnic Chinese patients with localized prostate cancer. BJU Int 110: E667-E672, 2012.

24. Lane BR, Stephenson AJ, Magi-Galluzzi C, Lakin MM and Klein EA: Low testosterone and risk of biochemical recurrence and poorly differentiated prostate cancer at radical prostatectomy. Urology 72: 1240-1245, 2008.

25. Botto H, Neuzillet Y, Lebret T, Camparo P, Molinie V and Raynaud JP: High incidence of predominant Gleason pattern 4 localized prostate cancer is associated with low serum testosterone. J Urol 186: 1400-1405, 2011.

26. He Y, Gu J, Strom S, Logothetis CJ, Kim J and Wu X: The prostate cancer susceptibility variant rs 2735839 near KLK3 gene is associated with aggressive prostate cancer and can stratify gleason score 7 patients. Clin Cancer Res 20: 5133-5139, 2014.

27. Tu H, Gu J, Meng QH, Kim J, Davis JW, He Y, Wagar EA, Thompson TC, Logothetis CJ and Wu X: Mitochondrial DNA copy number in peripheral blood leukocytes and the aggressiveness of localized prostate cancer. Oncotarget 6: 41988-41996, 2015.

28. Howlader N, Noone AM, Krapcho M, Garshell J, Miller D, Altekruse SF, Kosary CL, Yu M, Ruhl J, Tatalovich Z, et al: SEER Cancer Statistics, Review 1975-2011. http://seer.cancer. gov/csr/1975_2013/. Accessed September 12, 2016.

29. Cookson MS, Aus G, Burnett AL, Canby-Hagino ED, D'Amico AV, Dmochowski RR, Eton DT, Forman JD, Goldenberg SL, Hernandez J, et al: Variation in the definition of biochemical recurrence in patients treated for localized prostate cancer: The American Urological Association Prostate Guidelines for Localized Prostate Cancer Update Panel report and recommendations for a standard in the reporting of surgical outcomes. J Urol 177: 540-545, 2007. 
30. Roach M III, Hanks G, Thames H Jr, Schellhammer P, Shipley WU, Sokol GH and Sandler H: Defining biochemical failure following radiotherapy with or without hormonal therapy in men with clinically localized prostate cancer: Recommendations of the RTOG-ASTRO Phoenix Consensus Conference. Int J Radiat Oncol Biol Phys 65: 965-974, 2006.

31. Wang C, Nieschlag E, Swerdloff R, Behre HM, Hellstrom WJ, Gooren LJ, Kaufman JM, Legros JJ, Lunenfeld B Morales A, et al: Investigation, treatment, and monitoring of late-onset hypogonadism in males: ISA, ISSAM, EAU, EAA and ASA recommendations. J Androl 30: 1-9, 2009.

32. Endogenous Hormones and Prostate Cancer Collaborative Group, Roddam AW, Allen NE, Appleby P and Key TJ: Endogenous sex hormones and prostate cancer: A collaborative analysis of 18 prospective studies. J Natl Cancer Inst 100 $170-183,2008$

33. Ryan CJ, Molina A, Li J, Kheoh T, Small EJ, Haqq CM, Grant RP, de Bono JS and Scher H: Serum androgens as prognostic biomarkers in castration-resistant prostate cancer: Results from an analysis of a randomized phase III trial. J Clin Oncol 31: 2791-2798, 2013.

34. Ribeiro M, Ruff P and Falkson G: Low serum testosterone and a younger age predict for a poor outcome in metastatic prostate cancer. Am J Clin Oncol 20: 605-608, 1997.
35. Imamoto T, Suzuki H, Akakura K, Komiya A, Nakamachi H, Ichikawa T, Igarashi T and Ito H: Pretreatment serum level of testosterone as a prognostic factor in Japanese men with hormonally treated stage D2 prostate cancer. Endocr J 48: 573-578, 2001.

36. Yamamoto S, Yonese J, Kawakami S, Ohkubo Y, Tatokoro M, Komai Y, Takeshita H, Ishikawa Y and Fukui I: Preoperative serum testosterone level as an independent predictor of treatment failure following radical prostatectomy. Eur Urol 52: 696-701, 2007.

37. San Francisco IF, Rojas PA, DeWolf WC and Morgentaler A: Low free testosterone levels predict disease reclassification in men with prostate cancer undergoing active surveillance. BJU Int 114: 229-235, 2014.

38. Furuya Y, Nozaki T, Nagakawa O and Fuse H: Low serum testosterone level predicts worse response to endocrine therapy in Japanese patients with metastatic prostate cancer. Endocr J 49: 85-90, 2002.

39. Banach-Petrosky W, Jessen WJ, Ouyang X, Gao H, Rao J, Quinn J, Aronow BJ and Abate-Shen C: Prolonged exposure to reduced levels of androgen accelerates prostate cancer progression in Nkx3.1; Pten mutant mice. Cancer Res 67: 9089-9096, 2007.

40. Karantanos T, Evans CP, Tombal B, Thompson TC, Montironi R and Isaacs WB: Understanding the mechanisms of androgen deprivation resistance in prostate cancer at the molecular level. Eur Urol 67: 470-479, 2015. 